\title{
A NARRATIVIDADE DA EXPERIÊNCIA ADOTIVA - FANTASIAS QUE ENVOLVEM A ADOÇÃO
}

\author{
Daniela Botti da Rosa*
}

\section{RESUMO}

O presente artigo visa esclarecer os lutos e fantasias que envolvem o processo de adoção, entendido não apenas como o processo jurídico de adotar, mas de inscrever uma criança em uma simbologia familiar. Através da narratividade da experiência clínica, podemos fazer a interface dessas fantasias com contos de fadas e outras histórias literárias. Buscamos um olhar além da visão romantizada da adoção, que vê apenas o ato de amor envolvido, e deixa na obscuridade as fantasias que também estão implicadas para os pais biológicos, para os adotivos e para as crianças adotadas. Procuramos dialogar sobre sintomatologias neuróticas freqüentes em pessoas adotadas, tendo como referencial teórico a psicanálise e a noção de fantasias inconscientes.

Palavras-chave: adoção; fantasias; inconsciente; literatura; narratividade

\section{AbSTRACT}

NARRATION OF THE ADOPTIVE EXPERIENCE - FANTASIES THAT INVOLVE ADOPTION

The present article aims to clarify the mourning and fantasies that involve the adoption process, understood not only as a legal process, but one that inscribes the child in a familiar symbology. Through the narrativity of the clinical experience, we can make the interface between these fantasies, fairytales and other literary characters. We search to look beyond the romantic vision of adoption that only sees the act of love involved, and leaves in the blackness the fantasies that are also implied, for the biological parents, the adoptive ones, and the adopted children. We look to investigate the neurotic symptom in adopted children, having as our guide psychoanalytic theory and the notion of unconscious fantasies.

Keywords: adoption; fantasies; unconscious; literature; narrativity

* Mestranda em Letras e Lingüística pela Universidade Federal de Alagoas (UFAL); Psicóloga clínica com Pós-graduação em Psicologia Clínica pelo Centro de Estudos Superiores de Maceió (CESMAC); atua na Clínica Interdisciplinar Eunice Toledo - Maceió/AL. 
Direi - afinal de contas, o de que se trata é menos lembrar do que reescrever a história. (Lacan, [1953-1954]1986: 23)

Ao pensar sobre adoção, é comum que as pessoas tenham em mente idéias pré-concebidas. Por um lado, de um amor abnegado dos adotantes, de um sentimento de gratidão por parte dos adotados, de uma família especial, idealizada, onde reina o amor e o respeito. Por outro, a visão preconceituosa da adoção, de que um acerto desse tipo nunca poderá formar uma família "real" e que as crianças adotadas geralmente se tornam "problemáticas". Diante desse antagônico imaginário social, fica difícil perceber que, por trás das aparências, existem fantasias inconscientes sendo ativadas em cada membro de uma família adotiva, e que geralmente a gama de emoçōes em jogo é muito maior do que possamos imaginar em um primeiro olhar. Partimos da idéia de que, para além (ou aquém) desse imaginário, existem famílias e processos adotivos singulares. No entanto, pensamos poder reconhecer, a partir das demandas clínicas e da literatura pertinente, algumas fantasias que se atualizam e se ressignificam em grande parte dos casos.

Para tal, utilizamos o conceito psicanalítico de fantasia inconsciente (ou fantasma, para Lacan). Segundo Chemama (1995), fantasia para Freud seria "representação, argumento imaginário, consciente (devaneio), pré-consciente ou inconsciente, implicando um ou vários personagens, que coloca em cena um desejo, de forma mais ou menos disfarçada” (Chemama, 1995: 71). Dentre as fantasias, Freud distingue aquelas que chama de "originárias", que se relacionam com questôes da origem do sujeito, diretamente implicadas no tema da adoção, de que tratamos aqui. Estes fantasmas atualizam, giram em torno, por exemplo, da concepção do sujeito (fantasia da cena originária; romances familiares), da sexualidade (fantasia da sedução), ou da diferença entre os sexos (fantasias ligadas ao Complexo de Édipo e à Castração), ainda segundo Chemama (1995).

Ao nos aproximarmos dessas fantasias, também trazemos como pressuposto que as histórias literárias auxiliam tanto na construção da identidade e da narratividade própria de um sujeito, como na possibilidade das crianças - adotivas ou não - se ressignificarem suas fantasias, criando novas tramas a cada recontagem de sua própria história. "No vazio do papel em branco outra história podemos escrever, outra história podemos contar, empunhando um lápis, tomando a palavra" (Teixeira, 1998: 39). 


\section{As HISTÓRIAS INFANTIS NA CLÍNICA PSICANALÍTICA}

Ora, brincando com outras histórias e seus respectivos contadores, as crianças retomaram o seu fio narrativo e relacional. Isso porque os contos falam de tudo sem nada ameaçar e, por suas metáforas, podem trazer histórias terríveis, mas que, dentro do conto, deixam de ser ameaçadoras (Gutfreind, 2003: 147).

As histórias infantis sempre tiveram o poder de auxiliar as crianças a nomear e suportar seus conflitos básicos. Existem muitos estudos em Psicanálise sobre as características que fizeram os contos de fadas atravessarem séculos mantendo intacto o seu poder de atração. Talvez o mais conhecido seja o estudo de Bruno Bettelheim (1980), no qual o autor mostra, através da interpretação de vários contos, que as crianças identificam-se com as personagens, pois estas expressam ou personificam aspectos de seus dramas internos, sustentam tramas relacionadas às suas fantasias.

As histórias de fadas falam por metáforas, ou seja, expõem os dramas e fantasias da criança de forma simbólica, nos quais ela pode projetar-se, identificar-se, reconhecer-se apenas na medida das suas possibilidades. Os contos se tornam uma potencialidade não ameaçadora para a criança resolver ou buscar soluções para seus dilemas, por permitir que ela tenha certo controle sobre seus dramas internos através das narrativas. Salientamos, no entanto, que não consideramos apenas os contos de fadas como histórias que auxiliam a criança no seu desenvolvimento e na solução de seus conflitos, e nisso nos contrapomos a Bettelheim (1980). Pensamos que qualquer história que a criança use para enganchar suas fantasias pode ser aproveitada pelo terapeuta infantil para auxiliá-la a colocar em palavras suas angústias inomináveis. Se a criança criar histórias, é ainda melhor.

A nosso ver, alterações e criações são mais que bem-vindas, serão sempre uma oportunidade de movimentar as fantasias que fazem sofrer as crianças e suas famílias. As coisas ruins, patológicas, ficam escondidas nos cantinhos escuros da mente, produzindo angústia, medo, agitação e irritabilidade. Mas, se essas fantasias encontrarem algum tipo de tradução na narrativa do adulto e no diálogo com a criança, terão o potencial de oferecer alívio, cura e auxiliar no crescimento infantil (Corso \& Corso, 2006: 164).

Então... era uma vez... passamos a utilizar histórias literárias em nossa clínica com crianças e adolescentes, adotados ou não, para auxiliar na elaboração e ressignificação das fantasias que, volta e meia, prendem o sujeito em uma trama 
paralisante e sintomatizante. Na clínica psicanalítica, sempre se lidou com histórias, tramas, narratividades. Pensamos que a literatura pode ser mais um viés através do qual o sujeito se vê na possibilidade de deslizar de posição e se recontar. Partimos da idéia lacaniana de que a história de vida de um indivíduo é uma história sendo contada, em construção, constantemente atualizada pelas conexões significantes, pela forma como a luz de espanto, que é o inconsciente, toma forma, a cada instante. Como disse o próprio Lacan: "o fato de que o sujeito revive, rememora, no sentido intuitivo da palavra, os eventos formadores da sua existência, não é, em si mesmo, tão importante. O que conta é o que ele disso reconstrói” (Lacan, [1953-1954] 1986: 22).

\section{Medo do abandono, ou "João e Maria”}

Se existem temas repetidos, espécie de invariantes, em contos populares e também nos modernos, um deles é a separação, com ou sem abandono (Gutfreind, 2003: 175).

Algumas histórias, conforme temos verificado na clínica, tocam especialmente as crianças adotivas, trazendo ao trabalho questóes bastante profundas, relacionadas à fantasmática própria de uma situação de adoção. Uma dessas histórias é João e Maria (Tatar, 2004), que trata essencialmente da questão do abandono das crianças e de como elas lidam com ele. João e Maria são filhos de um lenhador muito pobre, que não consegue mais alimentar sua família. A madrasta das crianças o convence a abandoná-las na floresta para que não morram todos de fome. Para a criança adotiva, essa imagem pode representar o abandono sentido, e a falta de confiança naqueles que se propõem a alimentá-la. O abandono de João e Maria na floresta costuma provocar angústia e busca de esclarecimentos. "Por que os pais abandonaram eles?", "Eles fizeram alguma coisa errada?". Atualiza nas crianças o temor do abandono e a fantasia auto-acusatória de que mereceram o abandono, pois fizeram algo ruim.

A busca dos personagens por alimento remete a uma busca constante de amor, parece sempre haver uma demanda de amor. Muitas crianças adotadas, como já dissemos, se autodepreciam, achando que foram colocadas para adoção porque havia algo de errado com elas. Essa crença pode provocar uma dificuldade na formação de uma visão positiva de si mesmo como alguém que merece ser amado. Achando que era um bebê ruim, difícil, prossegue pensando que "eu não faço nada direito", e cada dificuldade soa como uma sentença: "por que eu nunca consigo aprender a andar de bicicleta?”. $\mathrm{Na}$ vida adulta, o indivíduo pode se tor- 
nar perfeccionista. Nada ou ninguém parece ser bom o bastante, pode exigir muito dos outros e de si mesmo, idealizando muito as pessoas, em especial as figuras femininas. Ou então, ao contrário, pode exigir pouco de si por acreditar que não pode oferecer muito, "contentando-se" com qualquer coisa, ficando aquém de suas possibilidades, não ocupando o seu lugar no mundo por acreditar não ter valor. O medo de ser difícil demais de lidar, e de que os pais desistam, pode também fazer com que a criança faça tudo para agradar, para parecer o filho perfeito, escondendo sentimentos desagradáveis, até explodir em crises de raiva. Nisso se junta o social, que exige gratidão dos adotados e reprime a mais leve manifestação de sentimentos ambivalentes em relação aos pais, já que estes "salvaram" a criança de uma vida de órfāo. Por essa via, vem a necessidade de retribuir sendo um bom filho. O sujeito não consegue apenas receber algo, sem retribuir, pois inconscientemente acredita não merecer, ficando eternamente em dívida.

Uma sintomatologia comum entre indivíduos que sofreram, ou acreditaram sofrer, rejeição são os "problemas de memória"; o esquecimento de pequenas ou grandes coisas reflete o sentimento de sentir-se esquecido, perdido, jogado fora. Uma adolescente adotada, que vem para atendimento com essa problemática da memória, entre outras coisas, nos pergunta certo dia: "O que você faz para lembrar de tudo isso que eu falo?", querendo na verdade perguntar "Você não vai esquecer de mim?". E inicia um processo de parar e retomar a terapia, um ciclo incessante de ausências e presenças para garantir que estaremos sempre lá, para ver se vamos ou não desistir dela. Nessa mesma linha sintomatológica está a tendência a perder coisas e a desistir muito fácil dos seus objetivos, assim como um dia uma mãe desistiu de seu bebê.

Segundo Viorst (2005), as perdas na infância - nas quais incluímos o abandono implicado no imaginário da criança adotiva, como origem de sua história podem fazer o indivíduo criar diferentes estratégias contra novas perdas: uma delas seria a indiferença emotiva, pela qual não se investe os objetos de amor para não correr o risco de perdê-los, não há sofrimento em perder aquilo que não se ama; outra estratégia seria a necessidade de cuidar dos outros como resgate, se tornando pessoas prestativas em cuidar dos outros da forma como gostariam ou deveriam ter sido cuidadas, mas isso não em nível consciente, e sim fantasmático; e uma terceira saída seria a autonomia prematura. Para não depender de ninguém, não precisar contar com ninguém, o sujeito torna-se independente precocemente, cuidando de si mesmo para não sofrer decepções, pois não confia que o outro não irá abandoná-lo. Ao menos duas dessas estratégias se referem a proteger-se de outras perdas passando de uma posição passiva para uma ativa, o indivíduo procura abandonar para não ser abandonado, provoca o abandono para parecer que 
tem algum controle sobre ele. Ou então busca fazer tudo o que puder de ruim para testar o amor de seus pais adotivos. Tomaso, um aluno da educadora Torey Hyden (1982), após passar por vários lares adotivos chega à classe perguntando: "Você me odeia?". Após a resposta negativa da professora, ele destrói toda a sala e os trabalhos dos colegas, e então retoma a pergunta: "E agora, você me odeia não é?" (Hyden, 1982: 65).

Uma forma comum de "testar" a família adotiva pode ser através do exercício de uma sexualidade precoce e desenfreada, inclusive algumas meninas engravidando ainda adolescentes. No nível fantasmático, essa é uma tentativa de identificação com a mãe biológica, para tentar reparar a sua história cuidando de seus filhos. Alguns "compensam" tornando-se pais ou mães muito apegados aos filhos, dependendo deles emocionalmente ou, então, no extremo oposto, repetem a história de abandono com seus próprios filhos. Aqui, o trabalho com as histórias, procurando auxiliar a elaboração e a reescritura da própria história pessoal, tem também objetivo profilático de não perpetuar a fantasmática do abandono através das geraçōes. Como bem disse Gutfreind: "Narrar pode ser, enfim, melhorar" (Gutfreind, 2003: 111).

Indivíduos que querem se proteger de novas perdas podem tentar fugir de emoções fortes, evitando relacionamentos profundos, tendo dificuldade de se envolver verdadeiramente no casamento, nas amizades, na terapia. Ainda crianças, se escondem atrás de um muro de afastamento que, segundo Filho e Schettini (2006), é sentido pela mãe adotiva como rejeição, deixando-a insegura como mãe. A insegurança faz com que a mãe, muitas vezes, não se "aproprie" da educação do filho, ou não se "aproprie" do próprio filho, temendo ser muito dura, visto que "ele já passou por tanta coisa”, não inscrevendo a criança na fantasmática familiar. Isso, por sua vez, é sentido novamente como rejeição pelo filho, e o ciclo continua...

Voltando à história de João e Maria, apesar de a cena inicial de abandono ser a que mais prende a atenção e as associações das crianças adotivas, também o encontro com a casa de doces traz algumas reflexões. Além de tratar novamente da questão da confiança que é quebrada - a casa que prometia ser acolhedora e se revelou ameaçadora -, remete ainda à idealização da família adotiva, em especial para crianças que são adotadas tardiamente (quando já não são mais bebês). Após um tempo vivendo provavelmente em abrigos, a criança idealiza a família adotiva e, quando percebe que nesse novo lar também existem regras e restrições, sente-se traída. É preciso que os pais estejam preparados para lidar com essas decepções, pois é fácil entrar conjuntamente com a criança nesse imaginário idealizado da casa de doces e permitir a ela que devore essa casa. As regras e o comprometimento 
no ato educativo de uma criança, no ato paterno e materno de filiação, de inscrição, implicam de certa maneira a derrubada de parte da casa de doces, mas certamente não a chegada da bruxa má.

\section{O PATINHO FEIO, O DIFERENTE, O ESTRANHO NO NINHO}

Deixe-me ver o ovo que não quer se partir - disse a velha pata. - Aposto que é de perua. Uma vez também me fizeram de boba, você não imagina o que passei com aqueles filhotes. Eles têm medo de água, você acredita? Não entraram no fosso de jeito nenhum. Grasnei e gritei tudo o que sabia, e nada. Esqueça esse ovo, vá ensinar seus outros filhos a nadar! (Andersen, 1995: 106).

É comum que, em lugar da verdade "você não nasceu da minha barriga, mas da barriga de outra pessoa, sua mãe biológica", se diga à criança que "você não nasceu da minha barriga, é filho do meu coração". Essa bem intencionada frase nega o nascimento como fruto da sexualidade, rompe com as questôes da sexualidade, há um silenciamento, nesse discurso, do fato de que uma criança é sempre fruto do sexo dos pais. Engendra-se pela palavra uma nova forma de ser filho, fruto apenas do amor, não do desejo, um amor (des)sexualizado. Para o adulto, ser filho do coração carrega uma mensagem de afeto, pois é no coração, e não na barriga, que "localizamos" o amor (localização simbólica), mas a criança pequena não é capaz dessa abstração, é comum ouvir-se que "eu não nasci, fui adotado". Tudo o que ela não quer é ser diferente dos outros, como o Patinho Feio da história de Hans Christian Andersen ([s.d] 1995), que não sabia da sua origem de cisne, mas sentia-se diferente de todos. Uma adolescente adotiva em atendimento se achava feia, com um problema de autodepreciação, tinha chegado até a automutilação - mordia os braços até arrancar pedacinhos da pele, fazia isso "distraidamente". Foi ela quem nos disse, certa vez, que se sentia como o Patinho Feio e a partir daí nós pudemos trabalhar sobre esses significantes: ver a automutilação como a raiva que ela sentia por não ser igual, raiva desse corpo que só mostrava a diferença, esse corpo que agredia o olhar cada vez que ela parava diante de um espelho - o espelho dos olhos -, essa pele de cor diferente que ela queria arrancar a mordidas, pois não era a mesma pele de sua família, de seus pais. E pudemos trabalhar a ressignificação do patinho feio em cisne - romper com essas fantasias, recontando a história de outra maneira, tecendo novas narratividades para a mesma trama. Romper, enfim, com um destino e, ao invés de permanecer no pensamento de que ela trazia uma marca negativa à família, ela pôde ver a sua diferença como possibilidade de trazer novos dizeres a essa família. 
O Patinho Feio lida com a sensação de estranhamento, de sentir-se um "estranho no ninho", e de sentir que sempre lhe falta algo que precisa buscar, dentro ou fora. A jornada do Patinho Feio é a jornada para dentro de si mesmo, para descobrir o que fazer com a sua história de vida descontínua. Algumas vezes os adotados se questionam com quem se parecem, e é inevitável que olhem de vez em quando para pessoas desconhecidas na rua e se perguntem se não poderia ser seu parente, em especial figuras femininas com a idade que teria sua mãe. Particularmente na adolescência, quando se consolidam as identidades masculino/feminina, há a curiosidade em saber como seria o pai ou a mãe, para saber como poderão ser enquanto homens e mulheres. Também há a preocupação com o histórico médico da família. Quem não gostaria de saber de que morreram seus antepassados? Com que idade? Sofriam de alguma doença genética, câncer, doença cardíaca? Houve casos de loucura na família?

Não apenas as crianças se interrogam dessa forma, mas também os pais adotivos. A cada impasse na vida ou na educação dos filhos, lidam com dúvidas a respeito das origens. Podem se perguntar, por exemplo, se os problemas de agressividade ou de aprendizagem do filho não estão relacionados à sua herança genética, ao uso de drogas ou álcool pela mãe biológica durante a gravidez. Novamente isso vem nos dizer de uma inscrição dessa criança na fantasmática familiar, colocando o acento sobre a adoção, e não se apropriando da história do filho. É preciso, segundo Queiroz (2004), que os pais possam percorrer o caminho entre o filho ideal e o filho real, para que esse último não fique colocado na posição de estranho, estrangeiro em sua família.

a criança [...] é estranhada pelos pais adotivos, por não pertencer ao mundo familiar, o da consangüinidade. Às vezes, o sentimento de estranhamento é projetado para fora e passam a viver o fantasma de rejeição social. Esse modo de ver o problema não anula um outro lado da questão, mais pro-ativo e promissor, qual seja: a maioria dos pais adotivos deseja e assimila seus filhos como pertencentes ao seio familiar (Queiroz, 2004: 106).

\section{Harry Potter e os romances familiares}

Nessa fantasia [o Romance Familiar do Neurótico], imaginamos sermos filhos adotivos, porque na verdade pertenceríamos a uma família em algum aspecto melhor do que aquela na qual crescemos. Com isso, demonstramos que nossos pais não estão à altura do que sonhamos, que nos amam pouco ou mal e, em seu lugar, convocamos, em devaneios, outra família idealizada, seja de um ami- 
go, de uma obra de ficção ou ainda criada puramente na fantasia (Corso \& Corso, 2006: 258) .

Segundo Eldridge (2004), algumas pessoas adotadas têm a sensação de que alguma coisa dentro delas está faltando. É o que os especialistas em adoção chamam de "dissonância cognitiva", e faz com que se envolvam em algum processo de busca, que pode ser literal, no sentido de procurar a família biológica para preencher os espaços vazios, ou pode ser uma busca simbólica, de entender "quem sou" e "a que lugar pertenço". Esse sentimento pode dar ao indivíduo uma sensação de irrealidade e uma necessidade muito grande de recorrer à fantasia. Como o famoso bruxinho Harry Potter (Rowling, 2000), que, se tornando órfāo, vai morar com os tios, e a sua insuficiente realidade faz com que se abram as portas de um mundo mágico, onde ele é importante, amado e protegido. Que criança desamparada já não criou um dia a fantasia de que alguém chegaria e a tiraria do mundo de miséria - financeira ou emocional - em que vive? A nova realidade de Harry Potter lhe parece um sonho, ou melhor, realiza seus sonhos mais secretos. Como nos fala Freud ([1919] 1996): "Há também todos os futuros, não cumpridos mas possíveis, a que gostamos ainda de nos apegar, por fantasia..." (Freud, [1919] 1996: 253).

Muitas crianças têm, em determinado momento, a fantasia de não serem filhos dos seus pais, de pertencerem a uma outra família, mais nobre, como Harry Potter. Os tios, que o criaram, figuram aqui nesse sentido como os pais reais, altamente decepcionantes, e os pais que morreram ficam inatingíveis, idealizados. É o que Freud ([1908] 1976) chama de Romances Familiares, nos quais “a imaginação da criança entrega-se à tarefa de libertar-se dos pais que desceram em sua estima, e de substituí-los por outros, em geral de uma posição social mais elevada" (Freud, [1908] 1976: 220). Há, portanto, uma fase em que a criança precisa se decepcionar com seus pais, percebendo que eles não são tão onipotentes, nem tão perfeitos, como ela sentia antes.

Segundo Viorst (2005) essa decepção é sentida como a perda dos heróis da infância, uma perda necessária para que a criança encontre novas pessoas para amar e imitar, e mesmo novas formas de amor. É necessário deixar morrerem estes pais perfeitos para poder aceitar a imperfeição do mundo. Para os adotados, o sonho de uma família perfeita, idealizada, que pudesse substituir a sua, é algo mais palpável, concreto, existe uma possibilidade. Nos devaneios da criança, mas especialmente do adolescente adotivo, pode existir um lugar privilegiado para as narrativas que apresentam esses romances familiares, como em Harry Potter. 
Além disso, os não-ditos ou as "revelaçôes" que envolvem o processo educativo da criança adotiva servem para manter algum espaço de mistério a respeito da origem, permitindo vôos imaginativos para dar conta da explicação das origens, tanto consciente como inconscientemente, cada qual na sua lógica própria. $\mathrm{O}$ não-dito é muito mais desestruturante que a verdade, seja ela qual for. Quando a adoção não é comentada, ficando no registro do não-dito, do inominável, que Lacan chamou o Real, o mito fundante da criança, que sempre se baseia no mito estruturante da família, esbarra em um segredo, em uma palavra que falta, falha e, em sua condição de hiância, buraco, vazio, se torna mais presente para o sujeito do que se tivesse sido enunciada. A respeito dessa mitologia familiar estruturante, Lacan fala: "Esse roteiro fantasístico apresenta-se como um pequeno drama, uma gesta, que é precisamente a manifestação do que chamo o mito individual do neurótico" (Lacan [1953] 2008: 25).

$\mathrm{Ou}$, então, ainda que a adoção seja comentada com a criança, muitas vezes cai na armadilha da "revelação", quando os pais assumem um tom solene e desnaturalizado ao falar disso com os filhos, mostrando que, ainda que se fale, o assunto é um tabu - individual, familiar, social - e fica alguma coisa por entender. O desconhecimento, ou o conhecimento desnaturalizado, pode provocar, no nível psíquico, a sensação de ser irreal, ou de viver em um mundo de fantasia. Muitas vezes pode ser difícil atingir uma identidade integrada, já que existem lacunas na história, e é preciso passar a vida em torno de descobrir "quem sou". As dificuldades na formação da identidade passam também pela existência de duas configurações de pais (os biológicos e os adotivos), ou seja, uma identidade dual, e uma história de vida descontínua, interrompida, na qual as fantasias preenchem os pedaços que faltam.

\section{Bem X Mal: os pais adotivos E as MÃes QUe abandonam}

sabe-se que freqüentemente prevalece, no espírito dos pais adotantes em dificuldade, um desmentido violento do valor suposto dos genitores de sua criança; o que tende a instaurar uma espécie de efeito narcísico negativamente - em bumerangue - entre os "abandonadores indignos" e os "ladrōes de crianças"... (Penot, 1996: 125).

Quando algo não vai bem na família adotiva, é comum que a "culpa" seja colocada em cima da adoção, não se enxerga que toda família tem seus problemas e conflitos, e muitas vezes as dificuldades de uma criança, ou a dificuldade dos pais em educar, não têm relação com o fato da adoção, mas com a disponibilidade 
emocional destes. Como vimos, uma grande parte dos pais adotivos consegue criar um espaço de desejo e inscrição familiar para seus filhos, mas não são esses casos que nos chegam na clínica. Nosso trabalho se refere a uma mediação entre pais e filhos adotivos, na possibilidade de construção - ou reconstrução, reformulação - desses laços de filiação. Convém salientar novamente que essas dificuldades não são exclusivas do processo de filiação por adoção, mas que nesses casos se revestem de configurações especiais.

É preciso, portanto, que os pais adotivos tenham criado, em si mesmos, um espaço de desejo para o filho, um desejo inconsciente, logo, que não se confunde com a vontade de adotar ou ter um filho. É a antinomia psicanalítica entre a vontade consciente e o desejo inconsciente. Uma gestação simbólica só pode ser realizada com sucesso depois que o luto pelo filho biológico que não veio for trabalhado internamente, para não deixar na vida familiar esse espaço como nãodito, referenciando a todo instante o filho real ao filho ideal. Articulada à idealização dos pais, reafirma-se a rejeição sentida pelo filho, e o ciclo continua. É preciso que algo rompa com essa cadeia homogênea de repetiçôes patogeneizantes e proponha a heterogeneidade, a aceitação íntima da diferença e do filho real.

Quanto ao tema da relação entre pais adotivos e biológicos, por mais que os pais mantenham uma relação aberta com os filhos em torno do tema da adoção e que se preparem para o dia em que eles vão querer procurar a família biológica, quando chega essa hora eles se sentem ameaçados, com medo de serem rejeitados pelo filho em nome de alguma ligação maior que ele teria com os pais biológicos. Os pais temem ficar órfãos dos seus filhos, o que reacende a luta que muitos travaram em torno da infertilidade. Seguindo essa mesma linha, podemos pensar a preferência por recém-nascidos como o desejo justamente de adotar uma criança sem história ou, melhor, que se acredita não ter história, para que possa se formar única e exclusivamente a partir dos pais adotivos.

As crianças percebem inconscientemente a rivalidade nos sentimentos dos pais adotivos em relação aos biológicos, como se fosse criada, em nível fantasmático, uma dualidade - bem X mal - recobrindo essa dupla configuração paterna. Por lealdade aos pais adotivos, muitos filhos só iniciam a busca pela família biológica tardiamente, embora esse fosse seu desejo há muito tempo; muitas vezes só buscam ativamente após a morte dos pais adotivos. Esse antagonismo se reflete, por exemplo, nas histórias criadas por um paciente, que sempre giravam em torno de uma bruxa má ou um feiticeiro do mal que faziam "coisas ruins" com as crianças e as deixavam passar fome até que alguém surgia na história, algum personagem salvador. Por outro lado, em algumas - poucas - histórias, ele nos contava que a 
bruxa na verdade não era má, era "do bem", mas se tornou "do mal" quando alguém lhe roubou seus bebês.

E, falando das bruxas más, podemos dizer que esse "lugar" no texto também reflete o lugar social das mães que abandonam ou entregam seus filhos para adoção, ou mães abandonadas, como coloca Motta (2005). São abandonadas porque delas não se quer falar, não se quer saber, existem poucos estudos sobre seus motivos e suas questóes ao abandonar um filho, e essa distância vem do mito do amor materno como universal e incondicional. O maior amor do mundo seria o da mãe pelo filho, portanto a sociedade nega e repele quem ousa desafiar esse aforismo sagrado.

A ideologia da maternidade vivida nos nossos dias e nascida com a sociedade burguesa patriarcal confere a todas as mulheres a faculdade natural de amar sem restrições e de cuidar da criança que concebeu sob quaisquer condições. As que recusam de algum modo este destino biológico e social são consideradas exceções e recebem com freqüência o rótulo de anormais (Motta, 2005: 63).

As mães que abandonam ou entregam seus filhos para adoção podem viver um luto sem fim e passar a vida procurando rostos na multidão que poderiam ser do seu filho perdido. Ainda segundo Motta (2005), é comum também que essas mulheres entrem em um ciclo de "gravidezes de repetição" para tentarem preencher a falta que o filho perdido deixa. A fantasia de reparação leva ao apego e superproteção dos outros filhos e à crença de que elas próprias não merecem receber amor, já que não foram capazes de oferecê-lo, o que dificulta seus relacionamentos interpessoais. Há ainda a esperança constante de rever o filho, e por essa fantasia de reunião fica mais difícil dizer adeus, as mães continuando a sonhar com os filhos, a criá-los em sua imaginação.

\section{CONSIDERAÇÕES FINAIS}

A nosso ver, tanto um filho biológico como um filho adotivo, desde que engendrados pelo desejo, terão condições de serem introduzidos em uma linhagem, uma vez que esta não se caracteriza pela função genética, mas pela função simbólica (Ducatti, 2003: 54).

Diante do exposto, apesar das generalizações necessárias ao estudo, acreditamos na singularidade da experiência adotiva, em uma narratividade peculiar a cada caso, a cada sujeito. A fantasmática da família adotiva, tanto para pais como para filhos, depende das condições de desejo dos pais, da possibilidade de estes 
inscreverem seus filhos na amarragem simbólica familiar, inscrevê-los em uma história que já começou a ser contada muito antes da chegada deles.

Nosso papel clínico geralmente é solicitado quando algo nesse processo de inscrição está dificultado pela fantasmática dos personagens ou da trama envolvida. É aqui que reiteramos o papel das histórias literárias como via de acesso ao inconsciente infantil, às constelaçôes de fantasias, rompendo com uma história que parecia já estar escrita, trazendo novas possibilidades de recontagem e reconstrução.

\section{REFERÊNCIAS BIBLIOGRÁFICAS}

Andersen, H. (s.d.). Histórias maravilhosas de Andersen. São Paulo: Companhia das Letrinhas, 1995.

Bettelheim, B. (1980). A psicanálise dos contos de fada. Rio de Janeiro: Paz e Terra.

Chemama, R. (org.). (1995). Dicionário de psicanálise. Porto Alegre: Artes Médicas.

Corso, D. \& Corso, M. (2006). Fadas no divã: psicanálise nas histórias infantis. Porto Alegre: Artmed.

Ducatti, M. (2003). A tessitura inconsciente da adoção. São Paulo: Casa do Psicólogo.

Eldridge, S. (2004). Vinte coisas que filhos adotados gostariam que seus pais adotivos soubessem. São Paulo: Globo.

Filho, L. S. \& Schettini, S. M. (orgs.). (2006). Adoção: os vários lados dessa história. Recife: Bagaço.

Freud, S. (1908). Romances familiares. Obras completas, ESB, v. IX. Rio de Janeiro: Imago, 1976.

(1919). O "estranho". Obras completas, ESB, v. XVII. Rio de Janeiro: Imago, 1996.

Gutfreind, C. (2003). O terapeuta e o lobo: a utilização do conto na psicoterapia da criança. São Paulo: Casa do Psicólogo.

Hyden, T. (1982). Filhos dos Outros. São Paulo: Melhoramentos.

Lacan, J. (1953). O mito individual do neurótico. Rio de Janeiro: Jorge Zahar, 2008.

- (1953-1954). O seminário, livro 1, Os escritos técnicos de Freud. Rio de Janeiro: Jorge Zahar, 1986.

Motta, M. A. P. (2005). Mães abandonadas: a entrega de um filho em adoção. São Paulo: Cortez.

Penot, B. (1996). Condição narcísica e emergência do sujeito: sobre a patologia adolescente de alguns adotados. In Corrêa, I. (org.). Mais tarde... é agora! Ensaios sobre a adolescência (pp. 119-137). Salvador: Ágalma. 
Queiroz, E. F. (2004). O "estranho" filho adotivo: uma leitura clinica do Unheimlich na adoção. Revista Latinoamericana de psicopatologia Fundamental, v. 7, no 4, 100-111. Rowling, J. K. (2000). Harry Potter e a Pedra Filosofal. Rio de Janeiro: Rocco.

Tatar, M. (2004). Contos de fadas - edição comentada e ilustrada. Rio de Janeiro: Zahar. Teixeira, A. B. R (1998). Fantasia de boneca. In Mengarelli, J. K. (org.). Dos contos, em cantos (pp. 32-40). Salvador: Ágalma.

Viorst, J. (2005). Perdas necessárias. São Paulo: Melhoramentos.

Recebido em 11 de outubro de 2007 Aceito para publicação em 4 de maio de 2008 